\title{
Electron impact ionization of water-doped superfluid helium nanodroplets: Observation of $\mathrm{He}\left(\mathrm{H}_{2} \mathrm{O}\right)_{n}^{+}$clusters
}

\author{
Shengfu Yang, Scott M. Brereton, Satvinder Nandhra, and Andrew M. Ellis ${ }^{a}$ \\ Department of Chemistry, University of Leicester, University Road, Leicester LE1 7RH, United Kingdom
}

Bo Shang, Lan-Feng Yuan, and Jinlong Yang

Hefei National Laboratory for Physical Sciences at the Microscale, University of Science and Technology of China, Hefei, Anhui 230026, People's Republic of China

(Received 28 February 2007; accepted 24 July 2007; published online 2 October 2007)

\begin{abstract}
Electron impact mass spectra have been recorded for helium nanodroplets containing water clusters. In addition to identification of both $\mathrm{H}^{+}\left(\mathrm{H}_{2} \mathrm{O}\right)_{n}$ and $\left(\mathrm{H}_{2} \mathrm{O}\right)_{n}^{+}$ions in the gas phase, additional peaks are observed which are assigned to $\mathrm{He}\left(\mathrm{H}_{2} \mathrm{O}\right)_{n}^{+}$clusters for up to $n=27$. No clusters are detected with more than one helium atom attached. The interpretation of these findings is that quenching of $\left(\mathrm{H}_{2} \mathrm{O}\right)_{n}^{+}$by the surrounding helium can cool the cluster to the point where not only is fragmentation to $\mathrm{H}^{+}\left(\mathrm{H}_{2} \mathrm{O}\right)_{m}$ (where $m \leqslant n-1$ ) avoided, but also, in some cases, a helium atom can remain attached to the cluster ion as it escapes into the gas phase. Ab initio calculations suggest that the first step after ionization is the rapid formation of distinct $\mathrm{H}_{3} \mathrm{O}^{+}$and $\mathrm{OH}$ units within the $\left(\mathrm{H}_{2} \mathrm{O}\right)_{n}^{+}$cluster. To explain the formation and survival of $\mathrm{He}\left(\mathrm{H}_{2} \mathrm{O}\right)_{n}^{+}$clusters through to detection, the $\mathrm{H}_{3} \mathrm{O}^{+}$is assumed to be located at the surface of the cluster with a dangling $\mathrm{O}-\mathrm{H}$ bond to which a single helium atom can attach via a charge-induced dipole interaction. This study suggests that, like $\mathrm{H}^{+}\left(\mathrm{H}_{2} \mathrm{O}\right)_{n}$ ions, the preferential location for the positive charge in large $\left(\mathrm{H}_{2} \mathrm{O}\right)_{n}^{+}$clusters is on the surface rather than as a solvated ion in the interior of the cluster. (C) 2007 American Institute of Physics.
\end{abstract}

[DOI: $10.1063 / 1.2772624]$

\section{INTRODUCTION}

Protonated water clusters, $\mathrm{H}^{+}\left(\mathrm{H}_{2} \mathrm{O}\right)_{n}$, have aroused intense scientific interest in recent years. These ions are known to be important in the chemistry of the upper atmosphere, ${ }^{1}$ but more fundamentally, they serve as model systems for gaining insight into the solvation structures and dynamics of protons in bulk aqueous solutions (see, for example, Ref. 2).

It has long been established that ionization of water clusters in the gas phase, whether by electron impact or by photoionization, leads to the formation of $\mathrm{H}^{+}\left(\mathrm{H}_{2} \mathrm{O}\right)_{n}$. The reaction taking place is

$$
\left(\mathrm{H}_{2} \mathrm{O}\right)_{n}+\left(h \nu \text { or } e^{-}\right) \rightarrow \mathrm{H}^{+}\left(\mathrm{H}_{2} \mathrm{O}\right)_{n-m-1}+m \mathrm{H}_{2} \mathrm{O}+\mathrm{OH} .
$$

The formation of protonated water clusters is thought to be favored over unprotonated water cluster ions, $\left(\mathrm{H}_{2} \mathrm{O}\right)_{n}^{+}$, by a large change in equilibrium structure between the neutral and cationic clusters. Consequently, vertical ionization deposits a relatively large amount of energy into the cation which is sufficient to induce cluster reorganization and which ultimately results in the loss of $\mathrm{OH}$. This process has recently been modeled using $a b$ initio molecular dynamics (AIMD) ${ }^{3,4}$ For $\left(\mathrm{H}_{2} \mathrm{O}\right)_{n}^{+}$clusters with up to six water molecules, the simulations indicate a two-step process in which ionization first induces a proton to move along a hydrogen bond towards the adjacent water molecule, resulting in the

\footnotetext{
${ }^{a)}$ Author to whom correspondence should be addressed. Electronic mail: andrew.ellis@le.ac.uk; Fax: +44(0)116 2523789
}

formation of an $\mathrm{H}_{3} \mathrm{O}^{+} \mathrm{OH}$ entity. This is followed by a second proton transfer to the next-nearest neighbor water molecule such that the $\mathrm{OH}$ now becomes more isolated from the positive charge, and thus is more weakly bound. According to the AIMD calculations, this second step results in the ejection of $\mathrm{OH}$ and the whole process is complete in $<300 \mathrm{fs}$ from the time of the initial ionization event. ${ }^{3}$

If $\left(\mathrm{H}_{2} \mathrm{O}\right)_{n}^{+}$ions are to survive the ionization process, some means of rapidly removing excess energy is required. This was first achieved by Shinohara et al., 5 who were able to quench the clusters by attaching argon atoms prior to photoionization. The argon provided a means of rapid evaporative cooling via the process

$$
\operatorname{Ar}_{m}\left(\mathrm{H}_{2} \mathrm{O}\right)_{n}+h \nu \rightarrow \operatorname{Ar}_{m-r}\left(\mathrm{H}_{2} \mathrm{O}\right)_{n}^{+}+r \mathrm{Ar} .
$$

In a subsequent study, Jongma et al. were able to show that this approach also works for electron impact ionization. ${ }^{6}$ Jongma et al. used the metastable decay of the cluster ions to demonstrate that evaporative cooling is indeed responsible for the survival of $\left(\mathrm{H}_{2} \mathrm{O}\right)_{n}^{+}$clusters.

An alternative means of quenching the parent cluster ion is to carry out the ionization in a helium nanodroplet. Helium nanodroplets provide a low equilibrium temperature $(0.4 \mathrm{~K})$, possess an exceptionally high thermal conductivity, and can dissipate energy rapidly by evaporative loss of weakly bound helium atoms. ${ }^{7}$ The release of gas phase $\left(\mathrm{H}_{2} \mathrm{O}\right)_{n}^{+}$cluster ions from this environment has previously been reported by Lewerenz et al. ${ }^{9}$ and Fröchtenicht et al. ${ }^{8}$ The investigation by Fröchtenicht et al. was concerned primarily with recording infrared spectra of neutral water clusters, and the electron 
impact mass spectrometry was used only as a means of indirectly monitoring variations in the abundance of neutral water clusters. The mass spectrum was dominated by $\mathrm{H}^{+}\left(\mathrm{H}_{2} \mathrm{O}\right)_{n}$, but much weaker signals due to unprotonated water cluster ions were also reported. The study by Lewerenz et al. also involved electron impact ionization mass spectrometry. Relatively low resolution mass spectra were obtained but unprotonated water cluster ions were reported as shoulders on the much stronger $\mathrm{H}^{+}\left(\mathrm{H}_{2} \mathrm{O}\right)_{n}$ peaks.

In this work, we have more closely investigated the electron impact mass spectrometry of water clusters in helium nanodroplets. Not only do we see both $\mathrm{H}^{+}\left(\mathrm{H}_{2} \mathrm{O}\right)_{n}$ and $\left(\mathrm{H}_{2} \mathrm{O}\right)_{n}^{+}$, as reported previously, but we also report observation of $\mathrm{He}\left(\mathrm{H}_{2} \mathrm{O}\right)_{n}^{+}$cluster ions for the first time. This finding persists across the full range of water cluster ions investigated, $n=4-27$, with no evidence of attachment of more than one helium atom. To aid interpretation of the mass spectra, $a b$ initio calculations have been carried out to explore the possible binding sites of the helium atom. On the basis of these calculations, we propose that the $\mathrm{He}\left(\mathrm{H}_{2} \mathrm{O}\right)_{n}^{+}$ions ejected from the helium droplet contain an $\mathrm{H}_{3} \mathrm{O}^{+}$-like entity at the cluster surface with a single dangling $\mathrm{O}-\mathrm{H}$ bond.

\section{EXPERIMENT}

The experimental arrangement has been described in earlier publications. ${ }^{10-12}$ Briefly, we used a pulsed helium nanodroplet source with the pulsed valve cooled to $12 \mathrm{~K}$ and a helium stagnation pressure of 14 bars. Under these conditions, the mean helium droplet size is in the region of 1.8 $\times 10^{4}$ helium atoms. ${ }^{12}$ The droplet expansion is collimated by a skimmer and then enters a pickup chamber where dopant gases can be added. For this work, water vapor was added to the droplet beam and the partial pressure was controlled via a high precision leak valve. Mass spectrometry was performed using an electron impact ionization source (100 eV impact energy) in combination with a reflectron time-of-flight mass spectrometer.

\section{COMPUTATIONAL DETAILS}

In support of the experimental work, $a b$ initio calculations have been performed on water cluster cations. Full scale calculations on large clusters were not feasible because of the size of the systems and the complex conformational landscape. Instead, we have focused on the dimer, $\left(\mathrm{H}_{2} \mathrm{O}\right)_{2}^{+}$, and tetramer, $\left(\mathrm{H}_{2} \mathrm{O}\right)_{4}^{+}$, with the latter being the smallest cluster ion showing clear evidence of helium atom binding in the experiments (see below). Both DFT-B3LYP and MP2 calculations were carried out using a $6-311++\mathrm{G}(2 \mathrm{~d}, 2 \mathrm{p})$ basis set. To correct for the basis set superposition error, which occurs for incomplete basis sets, the counterpoise correction was employed not only in the determination of the binding energy of the helium atom to the water cluster ion but also more fundamentally in the geometry optimizations. All calculations used the GAUSSIAN 03 software package. ${ }^{13}$

Harmonic vibrational frequencies were calculated for all the cluster ions and molecular fragments to account for zero point energies.

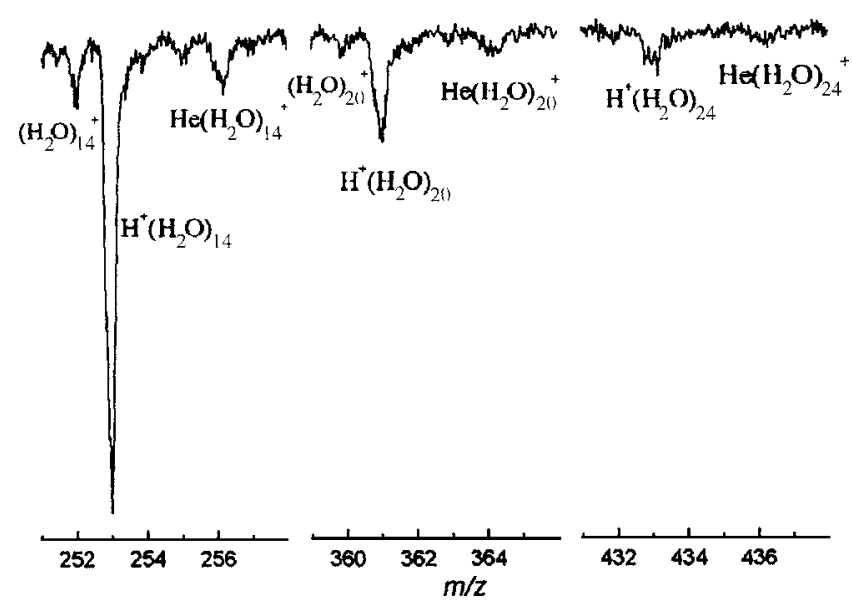

FIG. 1. The $n=14,20$, and 24 regions of the mass spectrum recorded from water clusters, $\left(\mathrm{H}_{2} \mathrm{O}\right)_{n}$, in helium nanodroplets. These data were obtained by averaging 6000 consecutive single-shot mass spectra at a repetition rate of $10 \mathrm{~Hz}$ (which corresponds to the repetition rate of the pulsed valve).

\section{RESULTS}

\section{A. Mass spectrometry}

The pickup of water molecules by helium droplets is a statistical process whose probability is determined by the helium droplet size and the partial pressure of the water vapor $\left(\sim 10^{-6}\right.$ mbar $)$. Under the conditions employed, water clusters ranging in size from 1 to 30 molecules could be observed in the mass spectra. Figure 1 illustrates the findings by showing sections of a mass spectrum in the region of the $n=14,20$, and 24 clusters. At these relatively large values of $n$, the contribution from bare $\mathrm{He}_{m}^{+}$cluster ions is small and, in addition, there is no significant contribution from trace background gases, which makes it easier to identify weak spectral features. However, the same pattern of peaks can be identified for all clusters in the range $n=4$ to $n=27$, although the relative intensities vary. Notice that no "magic number" ions were observed, which is consistent with a cooling effect by the helium droplets that makes the stability of particular cluster ion structures largely redundant.

The maximum observed cluster size was limited by the signal-to-noise ratio, which declined monotonically with $n$. The dominant peaks seen in the mass spectrum at $\mathrm{m} / \mathrm{z}$ $=18 n+1$ are due to $\mathrm{H}^{+}\left(\mathrm{H}_{2} \mathrm{O}\right)_{n}$ clusters, while the weaker peaks at $18 n$ arise from $\left(\mathrm{H}_{2} \mathrm{O}\right)_{n}^{+}$. In addition, there is another set of weak but significant peaks at $18 n+4$, which are assigned to $\mathrm{He}\left(\mathrm{H}_{2} \mathrm{O}\right)_{n}^{+}$. The $\mathrm{He}\left(\mathrm{H}_{2} \mathrm{O}\right)_{n}^{+}$peaks are noticeably broader than other peaks in the mass spectrum, particularly for low $n$. This peak width has proved advantageous in identifying $\mathrm{He}\left(\mathrm{H}_{2} \mathrm{O}\right)_{n}^{+}$. For example, the $n=4$ cluster has the same mass as the more abundant $\mathrm{He}_{19}^{+}$cluster, but $\mathrm{He}\left(\mathrm{H}_{2} \mathrm{O}\right)_{4}^{+}$ can still be identified as a broader feature underlying the much sharper and stronger $\mathrm{He}_{19}^{+}$peak. We have not been able to confirm or disprove the presence of $\mathrm{He}\left(\mathrm{H}_{2} \mathrm{O}\right)_{n}^{+}$clusters for $n=1-3$ due to severe interference from other mass spectral features in this region, so we can only say for certain that $\mathrm{He}\left(\mathrm{H}_{2} \mathrm{O}\right)_{n}^{+}$ions are formed for $n \geqslant 4$. However, if they are present at all, the abundance of $\mathrm{He}\left(\mathrm{H}_{2} \mathrm{O}\right)_{n}^{+}$relative to $\left(\mathrm{H}_{2} \mathrm{O}\right)_{n}^{+}$ clusters must be very low, since $\left(\mathrm{H}_{2} \mathrm{O}\right)_{2}^{+}$and $\left(\mathrm{H}_{2} \mathrm{O}\right)_{3}^{+}$give strong mass spectral signals. In fact, we find, as a general 


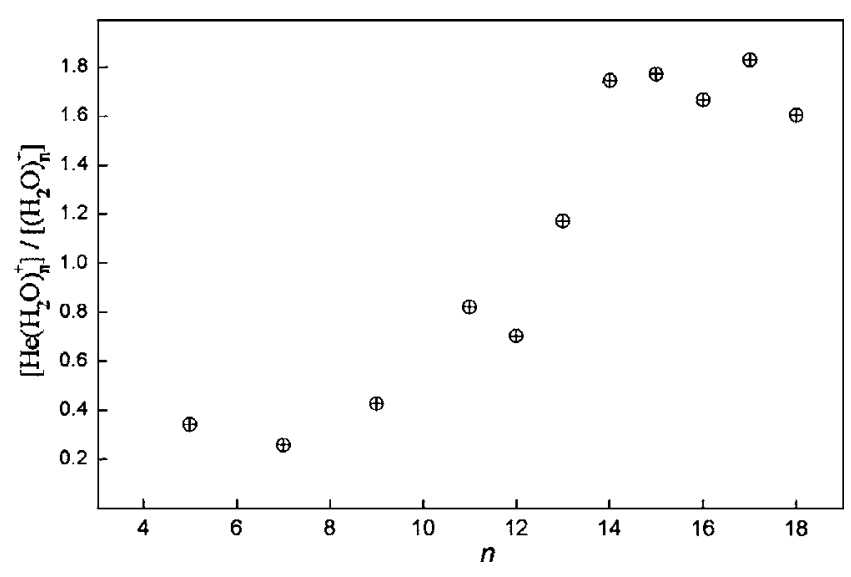

FIG. 2. Plot showing the variation of the $\mathrm{He}\left(\mathrm{H}_{2} \mathrm{O}\right)_{n}^{+} /\left(\mathrm{H}_{2} \mathrm{O}\right)_{n}^{+}$signal ratio (determined from peak areas) as a function of the number of water molecules, $n$. The ratios for some of the smaller clusters with an even number of water molecules are not plotted because of overlap with helium cluster peaks $\left(\mathrm{He}_{m}^{+}\right)$for both $\mathrm{He}\left(\mathrm{H}_{2} \mathrm{O}\right)_{n}^{+}$and $\left(\mathrm{H}_{2} \mathrm{O}\right)_{n}^{+}$.

trend, that the ratio of $\left(\mathrm{H}_{2} \mathrm{O}\right)_{n}^{+}$to $\mathrm{He}\left(\mathrm{H}_{2} \mathrm{O}\right)_{n}^{+}$declines as a function of $n$. As shown in Fig. 2, the point where the abundance of $\mathrm{He}\left(\mathrm{H}_{2} \mathrm{O}\right)_{n}^{+}$exceeds that of $\left(\mathrm{H}_{2} \mathrm{O}\right)_{n}^{+}$occurs at around $n=13$. It is also noteworthy that the $\mathrm{He}\left(\mathrm{H}_{2} \mathrm{O}\right)_{n}^{+} / \mathrm{H}^{+}\left(\mathrm{H}_{2} \mathrm{O}\right)_{n}$ signal ratio increases as $n$ increases. The precise cause of this trend is unknown, but it may be a simple matter of kinetics. Some $\mathrm{He}\left(\mathrm{H}_{2} \mathrm{O}\right)_{n}^{+}$cluster ions may be formed with residual energy sufficient to eject the helium atom, but as the cluster size increases the rate of decomposition will decrease, thus ensuring that an increasing proportion of the $\mathrm{He}\left(\mathrm{H}_{2} \mathrm{O}\right)_{n}^{+}$ions survives the journey to the ion detector.

In contrast to $\left(\mathrm{H}_{2} \mathrm{O}\right)_{n}^{+}$, there is no evidence of any protonated water clusters, $\mathrm{H}^{+}\left(\mathrm{H}_{2} \mathrm{O}\right)_{n}$, with one or more attached helium atoms. This observation will be discussed later.

\section{B. Ab initio calculations}

Before attempting calculations on $\mathrm{He}\left(\mathrm{H}_{2} \mathrm{O}\right)_{2}^{+}$and $\mathrm{He}\left(\mathrm{H}_{2} \mathrm{O}\right)_{4}^{+}$, the quality of the methodology was explored through a series of calculations on $\mathrm{HeH}_{3} \mathrm{O}^{+}$. The geometry of this cluster was fully optimized using a variety of basis sets and using DFT-B3LYP, MP2, and CCSD(T) methods. In all cases the equilibrium structure shows the helium atom binding to a single hydrogen atom and the sharing of a helium atom between two or all three hydrogen atoms corresponds to a transition state on the potential energy surface.

Table I shows the equilibrium $\mathrm{He}-\mathrm{H}$ distance and the He-H dissociation energy $\left(D_{e}\right)$ for the full set of calculations. We would expect the $\operatorname{CCSD}(\mathrm{T})$ calculations with the largest basis set employed, 6-311++G(2df,2pd), to yield the best representation of $\mathrm{HeH}_{3} \mathrm{O}^{+}$. However, such calculations would be prohibitively expensive for $\mathrm{He}\left(\mathrm{H}_{2} \mathrm{O}\right)_{2}^{+}$and $\mathrm{He}\left(\mathrm{H}_{2} \mathrm{O}\right)_{4}^{+}$, and so we must look for an acceptable lower level of theory to tackle the larger clusters. There are substantial discrepancies between the results from the highest quality $\operatorname{CCSD}(\mathrm{T})$ calculation and all the DFT-B3LYP calculations, with the $\mathrm{He}-\mathrm{H}$ bond lengths being much shorter for the latter and yielding a substantially higher dissociation energy. On the other hand, there is much closer agreement between the MP2 and $\operatorname{CCSD}(\mathrm{T})$ results. Furthermore, the dif-
TABLE I. Ab initio methods employed and quantities calculated for $\mathrm{HeH}_{3} \mathrm{O}^{+}$.

\begin{tabular}{llcc}
\hline \hline Method & Basis set & $r_{\mathrm{He}-\mathrm{H}}(\AA)$ & $D_{e}\left(\mathrm{~cm}^{-1}\right)$ \\
\hline CCSD(T) & $6-31 \mathrm{G}(\mathrm{d})$ & 2.0213 & 150.4 \\
& $6-311 \mathrm{G}(\mathrm{d})$ & 1.9482 & 200.1 \\
& $6-311++\mathrm{G}(\mathrm{d}, \mathrm{p})$ & 1.9156 & 213.6 \\
& $6-311++\mathrm{G}(2 \mathrm{~d}, 2 \mathrm{p})$ & 1.8546 & 292.4 \\
& $6-311++\mathrm{G}(2 \mathrm{df}, \mathrm{pd})$ & 1.8317 & 304.5 \\
MP2 & $6-31 \mathrm{G}(\mathrm{d})$ & 2.0379 & 135.3 \\
& $6-311 \mathrm{G}(\mathrm{d}, \mathrm{p})$ & 1.9717 & 189.6 \\
& $6-311++\mathrm{G}(\mathrm{d}, \mathrm{p})$ & 1.9309 & 202.2 \\
& $6-311++\mathrm{G}(2 \mathrm{~d}, 2 \mathrm{p})$ & 1.8662 & 273.8 \\
& $6-311++\mathrm{G}(2 \mathrm{df}, 2 \mathrm{pd})$ & 1.8454 & 283.8 \\
DFT-B3LYP & $6-31 \mathrm{G}(\mathrm{d})$ & 1.7712 & 416.8 \\
& $6-311 \mathrm{G}(\mathrm{d}, \mathrm{p})$ & 1.7189 & 394.3 \\
& $6-311++\mathrm{G}(\mathrm{d}, \mathrm{p})$ & 1.7079 & 351.0 \\
& $6-311++\mathrm{G}(2 \mathrm{~d}, 2 \mathrm{p})$ & 1.7207 & 394.5 \\
& $6-311++\mathrm{G}(2 \mathrm{df}, 2 \mathrm{pd})$ & 1.7135 & 399.5 \\
\hline \hline
\end{tabular}

ference in bond lengths and bond dissociation energies is relatively small in moving from the $6-311++\mathrm{G}(2 \mathrm{df}, 2 \mathrm{pd})$ to the $6-311++\mathrm{G}(2 \mathrm{~d}, 2 \mathrm{p})$ basis set, suggesting that the latter is likely to be acceptable for realistic calculations on the $\mathrm{He}\left(\mathrm{H}_{2} \mathrm{O}\right)_{2}^{+}$and $\mathrm{He}\left(\mathrm{H}_{2} \mathrm{O}\right)_{4}^{+}$ions. Consequently, for the calculations on $\mathrm{He}\left(\mathrm{H}_{2} \mathrm{O}\right)_{2}^{+}$and $\mathrm{He}\left(\mathrm{H}_{2} \mathrm{O}\right)_{4}^{+}$, we have employed the MP2 method with a 6-311++G(2d,2p) basis set.

To determine the structures of $\left(\mathrm{H}_{2} \mathrm{O}\right)_{2}^{+}$and $\left(\mathrm{H}_{2} \mathrm{O}\right)_{4}^{+}$, the known structures of the corresponding neutral water clusters were employed as the starting point. For $\left(\mathrm{H}_{2} \mathrm{O}\right)_{2}^{+}$, the only structure found can be described in terms of an $\mathrm{H}_{3} \mathrm{O}^{+}$ion attached through hydrogen bonding to an $\mathrm{OH}$ group. The formation of an identifiable $\mathrm{H}_{3} \mathrm{O}^{+}$entity is consistent with the expectation from AIMD calculations. ${ }^{3,4}$

As in the case of $\mathrm{HeH}_{3} \mathrm{O}^{+}$, a helium atom binds preferentially to a single hydrogen atom in $\mathrm{He}\left(\mathrm{H}_{2} \mathrm{O}\right)_{2}^{+}$. There are two isomers in this case, one where the helium atom is bound to the $\mathrm{H}_{3} \mathrm{O}^{+}$part of the cluster and another where the helium atom is bound to the $\mathrm{OH}$. These two isomers are shown as (a) and (b) in Fig. 3. Since the $\mathrm{H}_{3} \mathrm{O}^{+}$entity contains the bulk of the positive charge, the strongest binding for the helium atom would be expected at this part of the cluster

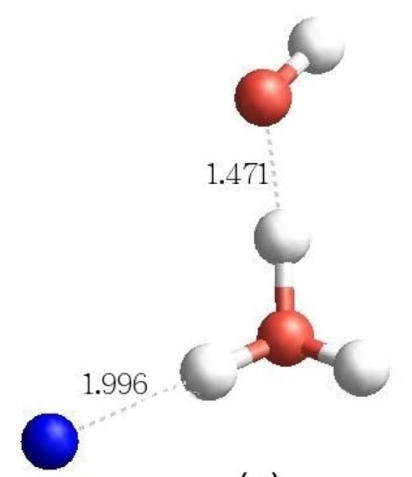

(a)

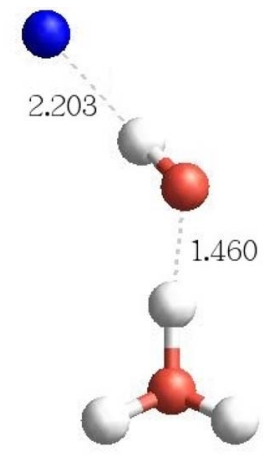

(b)
FIG. 3. (Color online) Calculated equilibrium structures for two isomers, (a) and (b), of $\mathrm{He}\left(\mathrm{H}_{2} \mathrm{O}\right)_{2}^{+}$. Bond distances are in angstroms. 
TABLE II. Calculated total energies, bond lengths, and dissociation energies of $\mathrm{He}\left(\mathrm{H}_{2} \mathrm{O}\right)_{2}^{+}$and $\mathrm{He}\left(\mathrm{H}_{2} \mathrm{O}\right)_{4}^{+}$.

\begin{tabular}{lccccc}
\hline \hline Cluster & Relative total & & & \\
& Isomer & & & \\
energy/eV & $r_{\text {He-H }}(\AA)$ & $D_{e}\left(\mathrm{~cm}^{-1}\right)$ & $D_{0}\left(\mathrm{~cm}^{-1}\right)$ \\
\hline $\mathrm{He}\left(\mathrm{H}_{2} \mathrm{O}\right)_{2}^{+}$ & (a) & 0.0099 & 2.2031 & 102.6 & 28.2 \\
& (b) & 0 & 1.9959 & 182.1 & 46.7 \\
$\mathrm{He}\left(\mathrm{H}_{2} \mathrm{O}\right)_{4}^{+}$ & $($a) & 0.1099 & 2.3719 & 62.3 & -22.7 \\
& (b) & 0.1055 & 2.1961 & 98.2 & 66.1 \\
& (c) & 0.2044 & 2.1189 & 150.0 & 130.7 \\
& (d) & 0.0003 & 2.3780 & 59.4 & 11.5 \\
& (e) & 0 & 2.3709 & 61.5 & 13.5 \\
\hline
\end{tabular}

${ }^{\mathrm{a}}$ This isomer labeling scheme refers to the structures shown in Figs. 3 and 4.

because of a substantial charge-induced dipole interaction. Confirmation is provided by the dissociation energies collected in Table II, which shows that attachment of the helium atom to the $\mathrm{OH}$ gives significantly weaker binding.

For $\left(\mathrm{H}_{2} \mathrm{O}\right)_{4}^{+}$, the formation of distinct $\mathrm{H}_{3} \mathrm{O}^{+}$and $\mathrm{OH}$ units is also observed but there are now three basic structures for the clusters, namely, cyclic, open chain, and interior. When a helium atom is added, these three basic water cluster structures lead to five distinct isomers, as shown in Fig. 4. Figures 4(a) and 4(b) show the cyclic isomer with a helium atom bound to the $\mathrm{OH}$ group and to the sole dangling $\mathrm{O}-\mathrm{H}$ bond of the $\mathrm{H}_{3} \mathrm{O}^{+}$unit, respectively. The equilibrium $\mathrm{He}-\mathrm{H}$ distances in these two isomers differ substantially and in fact the $\mathrm{OH}-$ bound species in (a) shows a negative dissociation energy $\left(D_{0}\right)$ for the $\mathrm{He}-\mathrm{H}$ interaction, i.e., this isomer is metastable with respect to the $\mathrm{He}+\left(\mathrm{H}_{2} \mathrm{O}\right)_{4}^{+}$dissociation products (see Table II). By far, the strongest binding of a helium atom occurs for the cyclic and open chain isomers (b) and (c), both of which contain an exposed $\mathrm{H}_{3} \mathrm{O}^{+}$unit with a dangling $\mathrm{O}-\mathrm{H}$ bond. The calculated binding energies $\left(D_{0}\right)$ are 66.1 and $130.7 \mathrm{~cm}^{-1}$, respectively.

Isomers (d) and (e) contain an $\mathrm{H}_{3} \mathrm{O}^{+}$unit at the center of the cluster around which is formed a solvation shell. The binding of helium atoms is weak in this case because the helium atom is distant from the main region of positive charge. Isomers (d) and (e) possess the lowest total energies, and so under equilibrium conditions would be expected to be the most abundant cluster ions. However, such conditions may not pertain in a helium droplet if cooling is rapid following ionization. The AIMD calculations of Tachikawa on the ionization dynamics of $\left(\mathrm{H}_{2} \mathrm{O}\right)_{4}$ are illuminating in this regard. Starting from the most stable, cyclic structure of $\left(\mathrm{H}_{2} \mathrm{O}\right)_{4}$, vertical ionization leads to rupture of the cyclic structure within $15 \mathrm{fs}$ and the formation of a recognizable open chain structure in $<100$ fs. These calculations suggest ejection of $\mathrm{OH}$ will occur in $\sim 300 \mathrm{fs}$ unless quenching takes place to ensure the survival of $\left(\mathrm{H}_{2} \mathrm{O}\right)_{4}^{+}$, which must clearly happen in helium droplets otherwise no $\mathrm{He}\left(\mathrm{H}_{2} \mathrm{O}\right)_{4}^{+}$would be observed. Consequently, the lowest energy structures for the $\left(\mathrm{H}_{2} \mathrm{O}\right)_{n}^{+}$clusters are not necessarily the important ones in explaining the helium droplet findings.

\section{DISCUSSION}

Molecular cations ejected from helium droplets tend to be observed without attached helium atoms. Nevertheless, the detection of molecular ions with attached helium atoms is not unique. For example, Callicoat et al. have observed $\mathrm{He}_{m} \mathrm{NO}^{+}$clusters with $m=1-15$ in the electron impact mass spectrum of $(\mathrm{NO})_{2}$ in helium nanodroplets. ${ }^{14}$ Similarly, Fárnik and Toennies have observed $\mathrm{He}_{m} \mathrm{CH}_{3}^{+}$and $\mathrm{He}_{m} \mathrm{CH}_{4}^{+}$ from methane in helium droplets, ${ }^{15}$ while Peterka et al. have reported $\mathrm{He}_{m} \mathrm{SF}_{k}^{+}$cluster ions from the vacuum ultraviolet photoionization of $\mathrm{SF}_{6}$ in helium droplets. ${ }^{16}$ However, one of the unusual aspects of the present work, when compared to earlier observations, is that we uniquely observe cations with only a single helium atom attached. $\mathrm{No} \mathrm{He}_{m}\left(\mathrm{H}_{2} \mathrm{O}\right)_{n}^{+}$ions with $m>1$ could be detected above the noise level, despite repeated searches. For low values of $n$, where the signal-tonoise ratio is at its best, we conclude that the $m=1$ clusters are at least 50 times more abundant than the $m>1$ clusters, if indeed the latter are present at all. The absence of $m>1$ clusters suggests that a particular stability can be attributed to the $\mathrm{He}\left(\mathrm{H}_{2} \mathrm{O}\right)_{n}^{+}$clusters.

The transfer of positive charge to molecules in helium droplets is thought to occur via a resonant charge hopping mechanism. ${ }^{17}$ This first involves the formation of $\mathrm{He}^{+}$somewhere in the droplet by electron impact, and the positive hole can then undergo several hops between adjacent helium atoms before it either becomes localized (to form $\mathrm{He}_{2}^{+}$) or it transfers irreversibly to the dopant molecule. The high first ionization energy of helium [24.587 eV (Ref. 18)] means that a large amount of excess energy can be deposited into the dopant ion, but dissipation of some or all of this energy is possible by helium atom evaporation from the ionized droplet. When first transferred over to the water cluster, the positive charge must reside on the surface of the cluster. Using the AIMD calculations as a guide, ${ }^{3}$ ejection of $\mathrm{OH}$ from this charged cluster is expected to take place in $\leqslant 300 \mathrm{fs}$, and clearly this must be the dominant process even in helium nanodroplets, as evidenced by the intense $\mathrm{H}^{+}\left(\mathrm{H}_{2} \mathrm{O}\right)_{n}$ signals in the mass spectrum. However, the mass spectrum also shows that a significant proportion of the ionization events do not follow this pathway, suggesting that in those cases rapid quenching on a subpicosecond time scale is successful, leading to the survival of some $\left(\mathrm{H}_{2} \mathrm{O}\right)_{n}^{+}$clusters.

The observation of $\mathrm{He}\left(\mathrm{H}_{2} \mathrm{O}\right)_{n}^{+}$provides clues about the structure and charge distribution in the $\left(\mathrm{H}_{2} \mathrm{O}\right)_{n}^{+}$clusters. First of all, we can conclude that the survival of $\mathrm{He}\left(\mathrm{H}_{2} \mathrm{O}\right)_{n}^{+}$clusters is highly unlikely unless the positive charge remains localized at the cluster surface, since only then will there be 


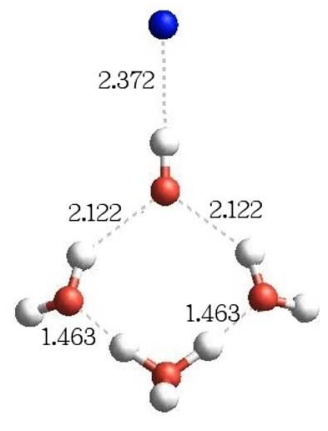

(a)

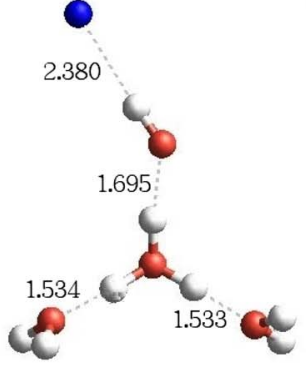

(d)

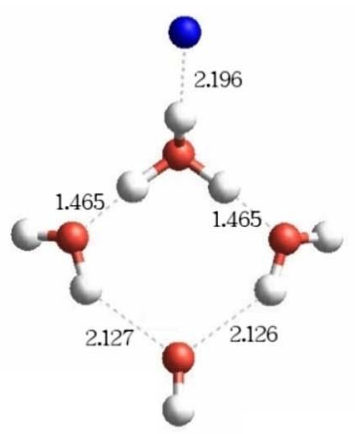

(b)

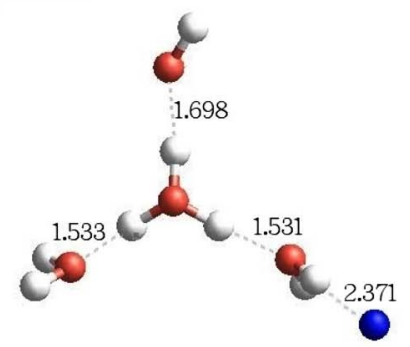

(e)

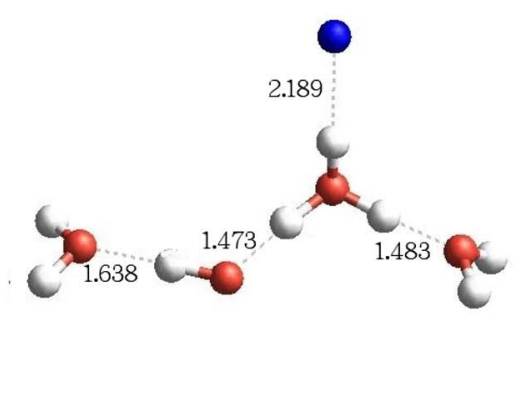

(c)
FIG. 4. (Color online) Calculated equilibrium structures for $\mathrm{He}\left(\mathrm{H}_{2} \mathrm{O}\right)_{4}^{+}$ showing five different isomers. Bond distances are in angstroms. a sufficiently strong charge-induced dipole interaction capable of retaining a helium atom. If the charge was not localized at a surface site, then not only would the stability of $\mathrm{He}\left(\mathrm{H}_{2} \mathrm{O}\right)_{n}^{+}$be reduced, but there would also be no reason to expect the survival of $\mathrm{He}\left(\mathrm{H}_{2} \mathrm{O}\right)_{n}^{+}$ions in preference to cluster ions with more than one helium atom attached. Small water clusters will not contain a fully solvated water molecule in the interior, but for $n \geqslant 17$ an internally solvated water molecule is possible. ${ }^{19}$ Consequently, the observation of $\mathrm{He}\left(\mathrm{H}_{2} \mathrm{O}\right)_{n}^{+}$clusters for up to $n=27$ suggests that, at least for a subset of the cluster ions, migration of the positive charge to an interior water molecule does not occur.

On ionization of $\left(\mathrm{H}_{2} \mathrm{O}\right)_{n}$ the AIMD calculations suggest that formation of an identifiable $\mathrm{H}_{3} \mathrm{O}^{+}$entity is so rapid ( $\sim 15 \mathrm{fs}$ ) that it is unlikely to be halted by any quenching process. ${ }^{3}$ We therefore assume that all the $\left(\mathrm{H}_{2} \mathrm{O}\right)_{n}^{+}$clusters contain this basic unit. The $a b$ initio calculations carried out in the present work demonstrate that the binding of a helium atom is much the strongest when attached to one of the hydrogen atoms on $\mathrm{H}_{3} \mathrm{O}^{+}$. We therefore propose that the observation of $\mathrm{He}\left(\mathrm{H}_{2} \mathrm{O}\right)_{n}^{+}$clusters is the result of $\left(\mathrm{H}_{2} \mathrm{O}\right)_{n}^{+}$ions being formed containing an $\mathrm{H}_{3} \mathrm{O}^{+}$unit exposed at the cluster surface with a single dangling $\mathrm{O}-\mathrm{H}$ bond. The two remaining $\mathrm{O}-\mathrm{H}$ bonds of the $\mathrm{H}_{3} \mathrm{O}^{+}$are assumed to be involved in hydrogen bonding, otherwise evidence for $\mathrm{He}_{2}\left(\mathrm{H}_{2} \mathrm{O}\right)_{n}^{+}$should have been found in the mass spectrum.

The observation of $\mathrm{He}\left(\mathrm{H}_{2} \mathrm{O}\right)_{n}^{+}$clusters begs the question as to why no helium atoms are seen attached to the far more abundant protonated water cluster ions, $\mathrm{H}^{+}\left(\mathrm{H}_{2} \mathrm{O}\right)_{n}$. The formation of $\mathrm{H}^{+}\left(\mathrm{H}_{2} \mathrm{O}\right)_{n}$ ions is the natural process resulting from vertical ionization of $\left(\mathrm{H}_{2} \mathrm{O}\right)_{n}$ and the observed $\mathrm{H}^{+}\left(\mathrm{H}_{2} \mathrm{O}\right)_{n}$ ions may be the result of little or no cooling by the helium matrix. Consequently, the absence of attached helium atoms can then be explained by the relatively high energy content of these clusters, which would lead to rapid evapo- ration of helium from the cluster surface prior to mass spectrometric detection. In addition, there is also a second reason why helium atoms may not attach to $\mathrm{H}^{+}\left(\mathrm{H}_{2} \mathrm{O}\right)_{n}$. Recent theoretical studies indicate that the $\mathrm{H}_{3} \mathrm{O}^{+}$unit in these ions is located at the cluster surface rather than in the interior, a location that maximizes polarization contributions to the binding energy. ${ }^{2,20-22}$ With this charge arrangement the three hydrogen atoms in $\mathrm{H}_{3} \mathrm{O}^{+}$are all involved in hydrogen bonding to neighboring water molecules and the oxygen atom acts as a hydrophobic site that bulges out from the surface. Such an arrangement is unfavorable for attaching a helium atom and would also work against $\mathrm{He} \cdot \mathrm{H}^{+}\left(\mathrm{H}_{2} \mathrm{O}\right)_{n}$ formation.

Finally, we comment briefly on the abnormal widths of the $\mathrm{He}\left(\mathrm{H}_{2} \mathrm{O}\right)_{n}^{+}$peaks. As mentioned earlier, these were observed to be notably broader than other peaks in the mass spectrum, particularly for $n<12$. The peak profile remains symmetric and slow (microsecond) metastable ion dissociation in the initial acceleration zone or in the drift tube region of the mass spectrometer cannot account for the broadening. Instead, we ascribe this observation to relatively large residual kinetic energies possessed by the $\mathrm{He}\left(\mathrm{H}_{2} \mathrm{O}\right)_{n}^{+}$cluster ions which are not fully compensated for by the two-stage reflection zone of the reflectron mass analyzer. To account for this, an "explosive" ejection of the cluster ion from the helium droplet would be required, but why this should occur selectively for $\mathrm{He}\left(\mathrm{H}_{2} \mathrm{O}\right)_{n}^{+}$and not for $\left(\mathrm{H}_{2} \mathrm{O}\right)_{n}^{+}$nor $\mathrm{H}^{+}\left(\mathrm{H}_{2} \mathrm{O}\right)_{n}$ (both of which show much narrower mass peaks) is unclear and may suggest some intriguing helium droplet fragmentation dynamics.

\section{CONCLUSIONS}

The electron impact mass spectrum of water-doped helium nanodroplets shows signals due to (i) $\mathrm{H}^{+}\left(\mathrm{H}_{2} \mathrm{O}\right)_{n}$, (ii) $\left(\mathrm{H}_{2} \mathrm{O}\right)_{n}^{+}$, and (iii) $\mathrm{He}\left(\mathrm{H}_{2} \mathrm{O}\right)_{n}^{+}$cluster ions. The dominant clus- 
ter ions are $\mathrm{H}^{+}\left(\mathrm{H}_{2} \mathrm{O}\right)_{n}$, which are also the dominant cationic species seen in the electron impact ionization of $\left(\mathrm{H}_{2} \mathrm{O}\right)_{n}$ clusters in the gas phase. The survival of $\left(\mathrm{H}_{2} \mathrm{O}\right)_{n}^{+}$ions requires rapid (subpicosecond) quenching by the liquid helium. The observation of $\mathrm{He}\left(\mathrm{H}_{2} \mathrm{O}\right)_{n}^{+}$ions in substantial quantities is particularly intriguing. Ab initio calculations on $\left(\mathrm{H}_{2} \mathrm{O}\right)_{4}^{+}$carried out as part of this work suggest that the ejection of $\mathrm{He}\left(\mathrm{H}_{2} \mathrm{O}\right)_{n}^{+}$ ions into the gas phase can be related to the structure and charge distribution of the $\left(\mathrm{H}_{2} \mathrm{O}\right)_{n}^{+}$ions. Ionization of $\left(\mathrm{H}_{2} \mathrm{O}\right)_{n}$ leads to rapid (barrierless) formation of $\mathrm{H}_{3} \mathrm{O}^{+}\left(\mathrm{H}_{2} \mathrm{O}\right)_{n} \mathrm{OH}$, and the observation of $\mathrm{He}\left(\mathrm{H}_{2} \mathrm{O}\right)_{n}^{+}$can be explained by the presence of the $\mathrm{H}_{3} \mathrm{O}^{+}$at the surface of the cluster with a dangling $\mathrm{O}-\mathrm{H}$ bond, which provides the point of attachment of the helium atom. This structural motif persists through to the largest clusters observed in the present work, $n=27$.

These conclusions are the first to be drawn on the structure and charge distributions in $\left(\mathrm{H}_{2} \mathrm{O}\right)_{n}^{+}$clusters. The current state of knowledge for $\left(\mathrm{H}_{2} \mathrm{O}\right)_{n}^{+}$lags far behind $\mathrm{H}^{+}\left(\mathrm{H}_{2} \mathrm{O}\right)_{n}$ clusters, for which experimental and theoretical studies are now rather advanced. There is clearly a need for further $a b$ initio calculations to establish the potential energy landscape of small, medium, and large $\left(\mathrm{H}_{2} \mathrm{O}\right)_{n}^{+}$clusters and we hope that the experimental and theoretical findings described in the present study will provide the motivation for such calculations.

\section{ACKNOWLEDGMENTS}

The authors are grateful to the UK Engineering and Physical Sciences Research Council for financial support of this work. One of the authors (S.Y.) would also like to thank the EPSRC for the award of an Advanced Research Fellowship.
${ }^{1}$ Chemistry of Atmospheres, edited by R. P. Wayne (Oxford University Press, Oxford, 1991).

${ }^{2}$ H.-C. Chang, C.-C. Wu, J.-L. Kuo, Int. Rev. Phys. Chem. 24, 553 (2005).

${ }^{3}$ H. Tachikawa, J. Phys. Chem. A 108, 7853 (2004).

${ }^{4}$ Y. V. Novakovskaya, Russ. J. Phys. Chem. 81, 216 (2007).

${ }^{5}$ H. Shinohara, N. Nishi, and N. Washida, J. Chem. Phys. 84, 5561 (1986).

${ }^{6}$ R. T. Jongma, Y. Huang, S. Shi, and A. M. Wodtke, J. Phys. Chem. A 102, 8847 (1998).

${ }^{7}$ J. P. Toennies and A. F. Vilesov, Angew. Chem., Int. Ed. 43, 2622 (2004).

${ }^{8}$ R. Fröchtenicht, M. Kaloudis, M. Koch, and F. Huisken, J. Chem. Phys. 105, 6128 (1996).

${ }^{9}$ M. Lewerenz, B. Schilling, and J. P. Toennies, J. Chem. Phys. 102, 8191 (1995).

${ }^{10}$ S. Yang, S. M. Brereton, M. D. Wheeler, and A. M. Ellis, Phys. Chem. Chem. Phys. 7, 4082 (2005).

${ }^{11}$ S. Yang, S. M. Brereton, M. D. Wheeler, and A. M. Ellis, J. Phys. Chem. A 110, 1791 (2006).

${ }^{12}$ S. Yang, S. M. Brereton, and A. M. Ellis, Rev. Sci. Instrum. 76, 104102 (2005).

${ }^{13}$ M. J. Frisch, G. W. Trucks, H. B. Schlegel et al., GAUSSIAN 03, Revision C.02, Gaussian, Inc., Wallingford, CT, 2004.

${ }^{14}$ B. E. Callicoatt, D. D. Mar, V. A. Apkarian, K. C. Janda, J. Chem. Phys. 105, 7872 (1996).

${ }^{15}$ M. Fárnik and J. P. Toennies, J. Chem. Phys. 122, 014307 (2005).

${ }^{16}$ S. S. Peterka, J. H. Kim, C. C. Wang, and D. M. Neumark, J. Phys. Chem. B 110, 19945 (2006).

${ }^{17}$ A. Scheidemann, B. Schilling, and J. P. Toennies, J. Phys. Chem. 97, 2128 (1993).

${ }^{18}$ NIST Chemistry Webbook, http://webbook.nist.gov

${ }^{19}$ A. Furuhama, M. Dupuis, and K. Hirao, J. Chem. Phys. 124, 164310 (2006).

${ }^{20}$ C.-C. Wu, C.-K. Lin, H.-C. Chang, J.-C. Jiang, J.-L. Kuo, and M. L. Klein, J. Chem. Phys. 122, 074315 (2005).

${ }^{21}$ S. S. Iyengar, M. K. Peterson, T. J. F. Day, C. J. Burnham, V. E. Teige, and G. A. Voth, J. Chem. Phys. 123, 084309 (2005).

${ }^{22}$ N. J. Singh, M. Park, S. K. Min, S. B. Suh, and K. S. Kim, Angew. Chem., Int. Ed. 45, 3795 (2006). 